\title{
BACHELOR DEGREE IN MEDICINE AND SURGERY COMMUNITY MEDICAL TRAINING CURRICULUM CONTRIBUTION ON EQUITY AND QUALITY OF HEALTH CARE, IN NAMIBIA.
}

\author{
Linda N Lukolo ${ }^{*}$, J Sheehama ${ }^{2}$, A Munyika ${ }^{3}$ \\ *1.2 School of Medicine, Faculty of Health Science, University of Namibia, Windhoek, Namibia \\ ${ }^{3}$ Oshakati Intermediate Hospital, Oshana region, Namibia
}

\section{*Corresponding Author: -}

Email:Inlukolo@unam.na

\begin{abstract}
: -
Community involving a population-focused, organized effort to help individuals, groups and communities reduce health risks, and maintain or improve health status". The Community Medicine departments of medical colleges should be more involved in integrated teaching with clinical disciplines and should also be involved in the delivery of services in the teaching hospital and in primary health care settings, such as in immunization, guidance/counselling, biomedical waste management and infection control. All stakeholders in university education recognize its invaluable contribution to the quality of university training. "Field Attachment" to mean any approved field-based practical work carried out by staff and students for the purpose of teaching and / or research in places outside the University control. The objective of community medicine-based training at the University is to produce practically oriented graduates that meet the required medical profession related competences of the community of their future service. Through community medicine attachment, medical students are enabled to associate themselves with the health and medical needs of the communities, this association will enable the students feel their own gap on these health issues to address them, or to be able to manage them.

Community medicine training placement also help the ministry of health and national at facility level to recognise the needs of the health system, and prepare to accommodate new graduate and new training program at these facilities of placement.

This study was to assess the contribution of community medicine-based training for undergraduate medical students at the University of Namibia. It has taken time to look at the availability of facilities of placement, number of students available for placement, and preparedness of different health facilities to accommodate medical students on communitybased education student's acceptance and satisfaction of students doing community medicine-based training.

The results of the study indicate that 10 (29.4\%) districts out of the 34 national health districts were available for community medicine-based training. It was only 20 (33.3\%) health facilities out of 60 facilities which were available to accommodate community-based training of medical students. The number of students available for community medicine placement increased from 43 students in 2012 to 290 for the year 2017 (77 are $3^{\text {rd }}, 724^{\text {th }}, 755^{\text {th }}$ and $666^{\text {th }}$ years) per year. It was only 9 (45\%) facilities that were ready to accommodate students arriving to them for community-based training in 2012. The acceptance of community medicine-based training was 39 (90.7\%) in 2012 and 246 (84.8\%) in 2017, while the satisfaction was 41 (95.3\%) in 2012 and 284 (97.9\%) in 2017.

The team could conclude that community based is very important for medical students, training as most of them in both 2012 and 2017 (90.7\% and 84.8\%) are welcoming the community medicine-based training. The satisfaction rate is very high and have even increased since inception of community-based training in 2012 from 95.3\% to $97.9 \%$ in 2017.
\end{abstract}

Key words: community medicine, training, placement, undergraduate, medical student

\section{() $($ (1)}




\section{BACKGROUND}

The University of Namibia, was tasked by the government of the Republic of Namibia to establish the medical training program, due to the need of more qualified doctors in the rural regions of Namibia (UNAM annual report 2009). Namibia has more foreign health professionals practicing in rural regions, due to the fact that, those very Namibian who receive medical training, outside Namibia, and complete their internship in Windhoek, choose to remain in the capital city while regional and district hospital, remain under staffed, or not staffed in some cases. The importance of community medical training in university training cannot be disputed and all stakeholders in university education recognize its invaluable contribution to the quality of Community based medical training curriculum of the University of Namibia. Community or field attachment programme therefore has brought the student out of the world of theory into real world. Through the programme students learn new skills, understand the people and environment of work, they learn how to live independently, put their theory into practice, learn institutions where they are placed and how they are managed. The programme usually contributes to effective preparation of the students for the market place (Barongo \& Lukolo, 2015)

Community Medical training is utilised by health science faculties worldwide to provide a relevant primary care experience for students and a service to underserved communities and, hopefully, to affect student career choices. The benefits to training institutions and students are well documented, but it may well be that communities, too, will be able to benefit from a more balanced partnership where they are consulted in the planning of such training programmes (Kelly, 2014)

\section{Literature}

Purpose of Community Medical training: The purpose of community training in the medical school is to produce practically oriented graduates that meet the required job - related competences of their field, it also serve as a linkage between the University and various health care partners who consume the services ( Mubuuke, 2008).

Community Medical training enable students get hand-on experience real- life situation they are expected to work in when they graduate, by doing so the student and academic staff interact with the health care workers from the Ministry of Health and other stakeholders and potential employers to appreciate field situations.

It enhances and strengthen linkage between the University, School of Medicine, Health facility partners, the students and the community. The benefits of the program for the different parties include: Students, Health system and families (Crampton, 2013).

\section{Methodology}

The School of Medicine at the University of Namibia opened its door in 2010 with 55 medical students this was done to meet the Namibia population health needs. Community training is part of School of Medicine curriculum where by students have to be placed to clinics, health centres, attached to families and to district hospitals.

During the second year of study, medical students are placed at clinics in Windhoek to learn the basic clinical skills, during the same year students are also attached to families with in various constituencies in Windhoek, this will help them to interact with the families and communities and to be oriented to real life situation.

During their third year, medical students attached to various hospitals throughout the country for community-based education and service (COBES). In 2012, a group of 45 third year medical students were deployed (for the first time at school) to various regions namely; Omusati, Oshana, Oshikoto, Ohangwena and Erongo region.

In 2013, a group of 79 students were deployed, a group consisted of 62 third year medical students and 17 second year pharmacy students to various regions, the number of regions has been expanded to accommodate the number of students, because they have been increasing from 45 students in 2012 to 246 in 2017. (Kunene, Kavango, Zambezi, Karas, and Omaheke).

During their $4^{\text {th }}$ year, medical students attached to district hospitals, with the aim to understudy the duties and responsibilities of a district medical officer. It is well known that medical officers face a number of administrative challenges in their day -to- day functioning because they seldom receive training in management and communication skills during their medical school, most of the facilities were not ready for the job of mentoring this student. With proper induction of the hospital team by the academic supervisors, made the exercise enjoyable to the team in the district hospital. Management skills for medical students is required because they are expected to be leaders as medical officers, they have to make the best use of limited resources available, and they should be good at multi -tasking. At district hospitals, medical students learn planning, organizing and evaluating all activities at the district level.

During $5^{\text {th }}$ and $6^{\text {th }}$ year medical students are attached to northern training hospitals such as; Oshakati Intermediate, Onandjokwe hospital and Medipark private hospital in Ongwediva, 


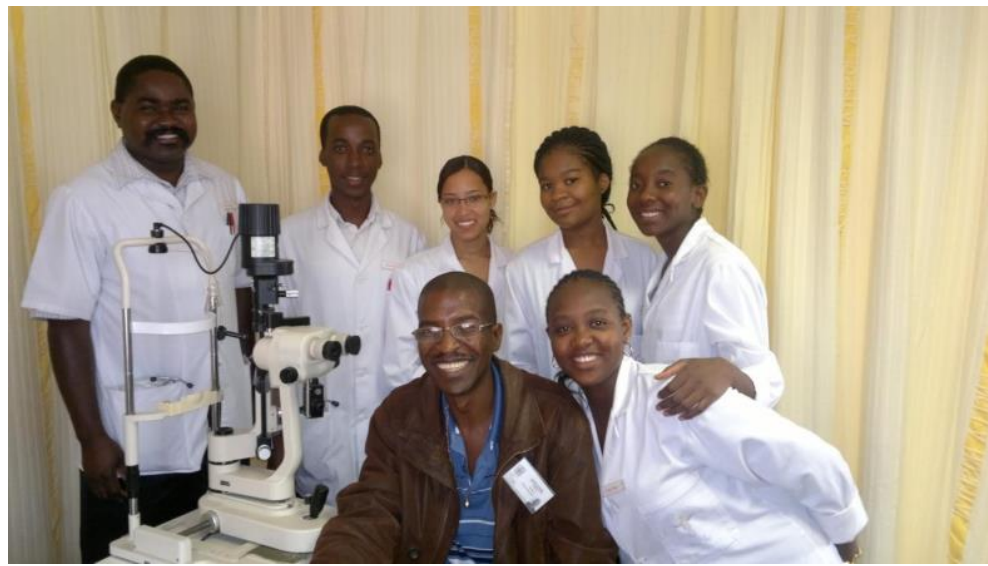

Image1: University of Namibia Medical Students: At the district hospital for training and the district hospital medical officer

\section{Medical students}

It is noted that medical students $(79 \%)$ on placement in the district hospital take their duties and responsibility in comparison to the when they are within their usual teaching hospitals in the city. The students will be able to identify health needs of the rural community. They will gain knowledge and skills that will enable them to understand the community and their health-related problems with the aim of undertaking disease prevention and control measures by end of placement $78 \%$ students were very confident to make presentation on disease control and prevention. They will acquire new knowledge and practical experiences and improve their confidence in problem solving. Students will receive opportunity to relate to different categories of people likely to be met in the real-life situation. They are exposure to the demands and challenges of the work place, they will also get the opportunity to work with personnel from the ministry of Health, Students will have improved appreciation of the profession and therefore better work ethics.

Students have experience in providing health care in a setting with limited resources, and they will appreciate the challenges involved in providing health care to medically underserved and impoverished populations. Community training insight the student into cultural diversity and the impact of culture in delivering health services. Students appreciate working with multidisciplinary team including nurses, health officers, attendants, village leaders and political figures.

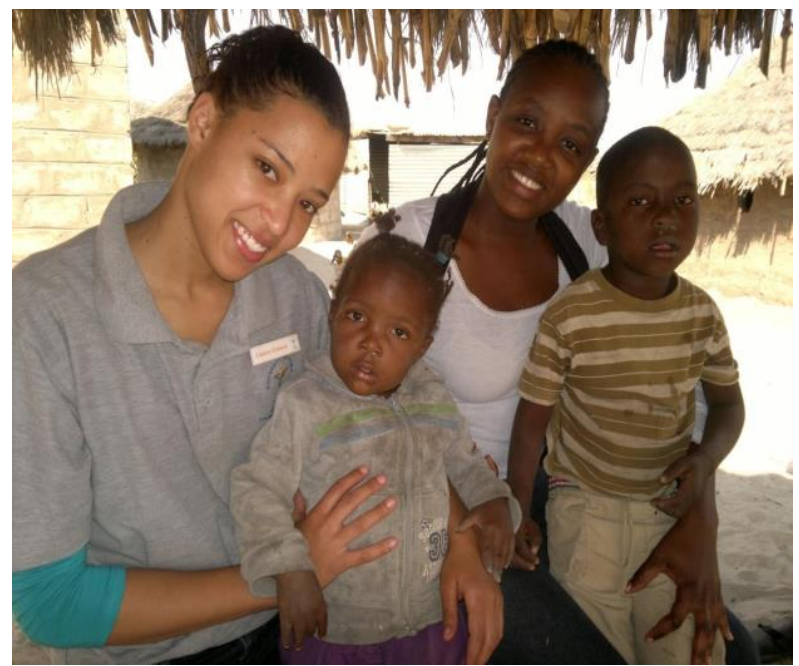

Image 2: University of Namibia Medical Students in community: Diversity of communities

They will understand the Socio-cultural environments from where patients come and understand the association between poverty, and diseases in the rural settings.

Through community training medical student will be able to identify major health problems affecting the community.

\section{Institutional School of Medicine}

The school gets opportunity to appreciate Health Facilities demand and the quality of graduate required to fulfil these demands, As a result of cooperation the potential for research will be enhanced and developed with the various health facilities,

The school gets opportunity to access training facilities and resources that are not available at the School. 


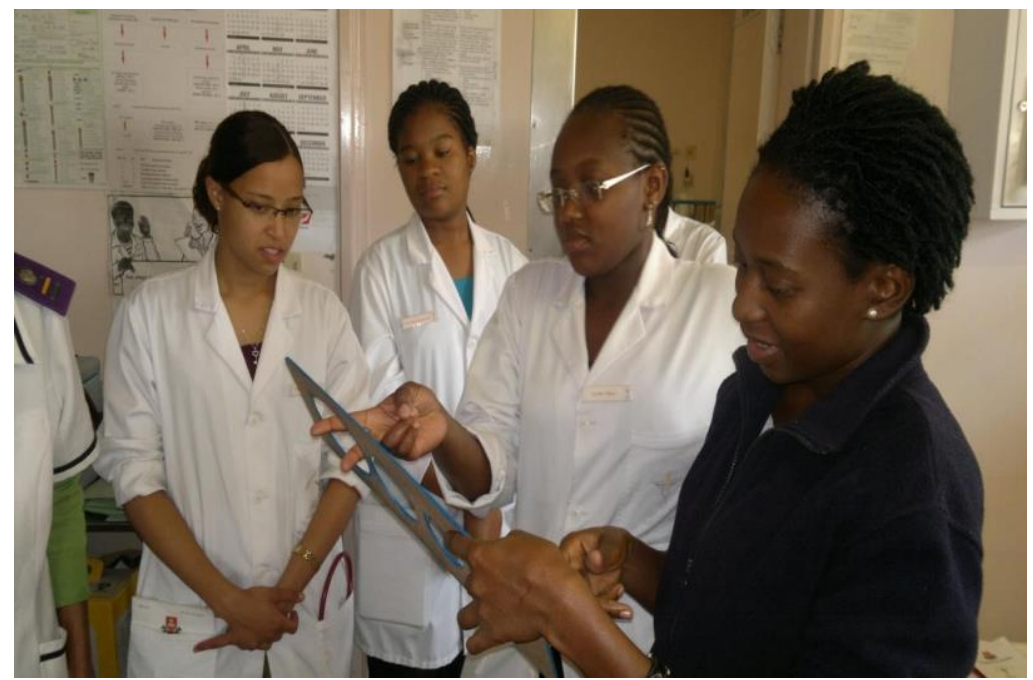

Image 3: Training in really life in progress.

Health facility and Communities: They got an opportunity to be involved in in the training and revision of the programs at School of Medicine. They will be engage in a mutual learning exercise together with the students and staff of school of medicine. The Health facility will get additional human resources for effective and efficient service delivery.

\section{Conclusions}

Students who went through community medicine based curriculum, have so far taken up position at district hospitals in the rural regions of Namibia. The retention of professionals in the regions participating in training if medical students have improved. The financing of the identified training regional hospital has received protestation. Overall the quality of healthcare services at the district hospitals hosting medical students have improved, and patients satisfaction have increased.

\section{References}

[1].African Journal of Primary Health Care \& Family Medicine | Vol 5, No 1 | a474 | DOI: https://doi.org/10.4102/phcfm.v5i1.474 |

[2].Barongo L, Lukolo L, 2015. MBCHB Community based education logbook, rural placement.

[3].School of Medicine , University of Namibia , Windhoek.

[4].Crampton PES, McLanhlan JC, Illing JC. Asystematic literature review of undergraduate clinical placements in underserved areas. Medical Education 2013;47(10): 969-970)

[5].Garg BS and Zodpey Sanjay- Status Paper on Public Health Courses in India, WHO India Country Office, New Delhi. 2006.

[6].Institute of Medicine of the National Academies, Who Will Keep the Public Healthy: Educating Public Health Professionals for the 21st Century. Washington, DC: National Academies Press; 2002. pp. 9-12.

[7].Kelly L, Walters L, Rosenthal D. Commnity-based medical education: is success a result of meaningful personal learning experience? Education Health 2014;27:47-50.

[8].Paula Diab, Penny Flack 2013 |This work is licensed under CC Attribution 4.0

[9].UNAM annual report 2009, Windhoek Namibia

[10]. Winslow CEA - The untilled filled of Public Health. Mod Med. 1920;2:183-91. 